\title{
Mães Órfãs: o direito à maternidade e a judicialização das vidas em situação de vulnerabilidade
}

Orphan mothers: the right to maternity and the judicialization of vulnerable lives

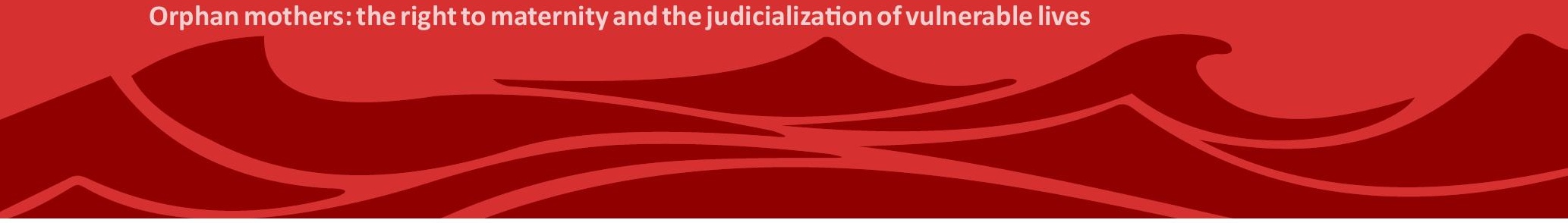

\section{Cristiana Marina Barros de Souza}

Mestranda da UFMG e Trabalhadora da saúde de $\mathrm{BH}$.

E-mail: cristianapsicologia@gmail.com

\section{Mônica Garcia Pontes}

Mestranda da UFMG e Diretora de escola em Contagem.

E-mail:monicagpontes78@gmail.com

\section{Alzira de Oliveira Jorge}

Doutora em Saúde Coletiva e Professora da UFMG.

E-mail: alziraojorge@gmail.com

\section{Ricardo Narcizo Moebus}

Doutor em Ciências da Saúde e Professor da UFOP.

E-mail: ricardo.moebus@gmail.com

\section{Daniel Emílio da Silva Almeida}

Mestre em Saúde Pública e Trabalhador da saúde de $\mathrm{BH}$.

E-mail: daniel.almeidamg@gmail.com

\section{Resumo}

Objetivos: Caracterizar a problemática vivenciada em Belo Horizonte $(\mathrm{BH})$ sobre a separação compulsória de mães e filhos em famílias vulneráveis. Métodos: Foram utilizados para a análise: fontes documentais por meio das normas vigentes, relatos e reflexões obtidas em seminários realizados sobre o tema na cidade e entrevistas com trabalhadores da saúde, agentes do estado, judiciário e movimentos sociais e ainda narrativas com mães que foram separadas de seus filhos de forma compulsória. Resultados: Recomendações e Portaria do judiciário em BH têm orientado o processo de expropriação dos bebês. Tais normativas desconsideram as singularidades existentes nas vidas das mães e, neste cenário, os profissionais de saúde são capturados em sua autonomia. Nos relatos de mães e trabalhadores, a violência cotidiana, ditada pelo poder do Estado, aparece marcada por julgamentos morais, massacre de desejos maternais, tentativa de controle total do corpo do outro. Movimentos de diversos setores da sociedade têm se organizado na defesa dos direitos à maternagem e à convivência familiar. $\mathrm{Em} \mathrm{BH}$, são explícitos os posicionamentos e disputas com importantes desdobramentos para a vida de mulheres marcadas pelo poder do Estado. Considerações Finais: Na atualidade, vivemos momentos de acirramentos importantes entre instituições, coletivos e apostas ético-políticas no que diz respeito ao governo da vida de si e dos outros, considerando o arranjo societário no qual estamos imersos. A judicialização de vidas 
vulneráveis e a insuficiente porosidade das mobilizações em defesa do direito à maternidade em nossa sociedade têm mostrado arranjos sociais que interferem na construção de novas possibilidades de cuidado em saúde.

Palavras-chave: Violência contra a mulher; Judicialização da saúde; Vulnerabilidade social.

\section{Abstract}

Objectives: To typify the problems experienced in Belo Horizonte $(\mathrm{BH})$ regarding the compulsory separation of mothers and children in vulnerable families. Methods: Documentary sources were used for analysis through current norms / guidelines, reports and reflections obtained in seminars held on the subject in the city and interviews with health workers, state and judicial agents, social movements and with mothers who were separated from their children compulsorily. Results: Recommendations and Ordinance of the judiciary have guided the process of expropriation of babies. Such regulations disregard the singularities existing

\section{Introdução}

\section{A Sociedade de Sequestro e As Mães Órfãs do Leviatã}

Maria procura um hospital de Belo Horizonte já em trabalho de parto, sendo internada para ter seu bebê. O parto ocorre sem intercorrências, nascendo um bebê a termo e saudável.

Maria é uma mulher negra, pobre, mãe solteira, desempregada, tem trajetória de rua, história de algum uso de drogas ilícitas, como maconha, e lícitas, como álcool e benzodiazepínicos.

Maria quis ter esse bebê, quer criar seu filho e a in the lives of mothers and, in this scenario, health professionals have their autonomy captured. In the reports of mothers and workers, the daily violence dictated by state power is marked by moral judgments, a massacre of maternal desires, and an attempt to control the body of the other. Movements from various sectors of society have been organized in the defense of the rights to motherhood and family coexistence. In $\mathrm{BH}$, the stances and disputes are explicit with important unfoldings for the life of women marked by the power of the State. Final Considerations: At present, we are experiencing moments of great importance among institutions, collectives and ethical-political bets regarding the government of the life of the self and others, considering the societal arrangement in which we are immersed. The judicialization of vulnerable lives and the insufficient porosity of the mobilizations in defense of the right to motherhood in our society have shown social arrangements that interfere in the construction of new possibilities of health care.

Keywords: Violence against women; Judicialization of Health; Social Vulnerability.

partir dele reinventar sua vida que esteve à deriva por algum tempo.

Alguém avisa Maria que não permitirão que ela fique com a criança, que ela receberá alta, mas a criança permanecerá no hospital e dali será encaminhada para abrigamento e rápida adoção, porque Maria é considerada uma mãe não confiável pelo Estado.

Maria consegue sair com seu próprio bebê escondido em uma sacola, daí ela se esconde junto com o bebê em áreas de ocupação "irregular", longe do olhar panóptico do Estado. 
Quando a instituição percebe que ela saiu com o bebê, já é tarde demais para tomá-lo dela, ela desapareceu, é considerada uma criminosa, é procurada pela polícia, mas ninguém a encontra.

Ela fica, cuida, amamenta e cria seu bebê que cresce saudável, a despeito de todas as suspeitas de sua competência para a maternagem.

Essa não é uma história inventada, por mais inverossímel que possa parecer, é um relato real de uma das mães que conseguiram escapar da máquina capturante de bebês.

Nem mesmo o sonho racionalista do Leviatã de Hobbes pensou tanta intervenção sobre a vida particular, mas, pelo contrário, ressalvava o direito materno:

Se não havia contrato, o domínio era da mãe. Com efeito, na condição de mera natureza, sem leis matrimoniais, ignora-se quem é o pai, a menos que seja declarado pela mãe; portanto, o direito de domínio sobre a criança depende da vontade daquela e em consequência lhe pertence. Ademais, visto que o infante está primacialmente sujeito ao poder materno, de tal forma que ela pode nutri-lo ou expô-lo, se ela o alimenta e protege, ele the deve a vida, ficando, portanto, obrigado a obedecer-lhe preferencialmente a qualquer outra pessoa; por conseguinte, pertence a ela o domínio sobre ele. ${ }^{1}$

Vale lembrar que esse respeito ao direito materno é declarado mesmo no contexto do absolutista Leviatã:

Assim é gerado aquele grande LEVIATÃ, ou melhor, para falar mais reverentemente, aquele Deus mortal ao qual devemos, abaixo de Deus imortal, nossa paz e nossa defesa. Com efeito, por meio dessa autoridade que lhe é conferida por todo e cada um dos indivíduos que constituem o Estado, ele passa a dispor de tanto poder e tanta força que, pelo terror desse poder e dessa força, ele se torna capaz de conformar as vontades de todos à paz no interior do país, e à ajuda mútua contra o inimigo externo.

Mas o que justificaria tamanha intervenção em inúmeras situações em que não se configura de forma alguma a negligência, maus tratos, situações de abuso ou de abandono contra esses bebês que acabaram de nascer, que estão sendo carinhosamente amamentados por suas mães?

A justificativa é aquela moderna invenção do século XIX, de periculosidade, como nos ensina didaticamente Foucault:

[...] toda a penalidade do século XIX passa a ser um controle, não tanto sobre se o que fizeram os indivíduos está em conformidade ou não com a lei, mas ao nível do que podem fazer, do que são capazes de fazer, do que estão sujeitos a fazer, do que estão na iminência de fazer. Assim, a grande noção da criminologia e da penalidade em fins do século XIX foi a escandalosa noção, em termos de teoria penal, de periculosidade. A noção de periculosidade significa que o indivíduo deve ser considerado pela sociedade ao nível de suas virtualidades e não ao nível de seus atos; não ao nível das infrações efetivas a uma lei efetiva, mas das virtualidades de comportamento que elas representam. ${ }^{2}$

As mães cujos corpos não sejam considerados suficientemente controlados pelo Estado serão então consideradas incompetentes para a maternagem, ou, ao menos, para uma certa maternagem esperada e preconizada para a formação dos corpos para o trabalho, por um Estado regente de uma sociedade de controle, sociedade de sequestro: 
Já nas instâncias de controle que surgem a partir do século XIX, o corpo adquire uma significação totalmente diferente; ele não é mais o que deve ser supliciado, mas o que deve ser formado, reformado, corrigido, o que deve adquirir aptidões, receber um certo número de qualidades, qualificar-se como corpo capaz de trabalhar. Vemos aparecer assim claramente a segunda função. A primeira função do sequestro era de extrair o tempo, fazendo com que o tempo dos homens, o tempo de sua vida, se transformasse em tempo de trabalho. Sua segunda função consiste em fazer com que o corpo dos homens se torne força de trabalho. ${ }^{2}$

Esta sociedade de sequestro, que se permite inclusive sequestrar os bebês de mães que forem antecipadamente consideradas "insuficientemente controladas", se apoia e encontra sua justificativa maior na "gestão dos riscos", para usar esta célebre expressão de Robert Castel:

As novas estratégias médico-psicológicas e sociais se pretendem, sobretudo, preventivas, e a prevenção moderna se quer, antes de tudo, rastreadora dos riscos. Um risco não resulta da presença de um perigo preciso, trazido por uma pessoa ou um grupo de indivíduos, mas da colocação em relação de dados gerais impessoais ou fatores (de riscos) que tornam mais ou menos provável o aparecimento de comportamentos indesejáveis. Pode haver aí associações de riscos, quer dizer, correlações de fatores independentes: ter nascido, por exemplo, de mãe solteira que é também empregada doméstica (ou sem profissão, estrangeira, estudante, assalariada agrícola...), menor de dezessete anos (ou mais de quarenta), tendo tido um número de gravidezes superior às taxas médias segundo a idade, etc. A presença de tais fatores basta para desencadear um assinalamento automático, em virtude do axioma de que uma "mãe de riscos" engendra, ou cria, filhos de riscos. Assim, prevenir é primeiro vigiar, $[\ldots] .^{3}$

\section{Métodos}

O presente texto foi elaborado com o objetivo de caracterizar a problemática vivenciada em Belo Horizonte (BH) acerca da separação compulsória de mães e filhos de famílias vulneráveis. Os pesquisadores do Observatório de Políticas e Cuidado em Saúde da UFMG, de posse dos pareceres dos Comitês de Ética em Pesquisa ( $n$ o 1.847.486 CEP/SMSA-BH; $\mathrm{n} \cong 2.264 .660$ CEP/UFMG; $n$ 1.756.736 CEP/Nacional), buscaram fontes documentais sobre o tema e sobre os casos de retirada de bebês de mães em situação de vulnerabilidade social em $\mathrm{BH}$. Realizaram entrevistas com trabalhadores dos serviços de saúde, agentes do estado e judiciário, movimentos sociais e com as próprias mães para a construção de narrativas de si.

Neste percurso foram identificadas formas de expressão da sociedade sobre o assunto e a equipe de pesquisadores conquistou parcerias para a realização de seminários sobre o tema. Os encontros dos pesquisadores com diversos segmentos da sociedade, em especial as mães em situação de vulnerabilidade, a Faculdade de Enfermagem da UFMG, a Faculdade de Direito e Ciências do Estado da UFMG, ONGs envolvidas com a temática, organizações feministas, Conselho Municipal de Saúde de $\mathrm{BH}(\mathrm{CMSBH})$, Clínica de Direitos Humanos da UFMG, 4ạ Defensoria da Infância e Juventude Cível de BH, Defensoria Especializada em Direitos Humanos, entre outros, proporcionaram reflexões que culminaram com a produção deste artigo e com a ratificação do compromisso do Observatório de Políticas e Cuidado em Saúde da UFMG de avaliar a instituição, implementação e os 
impactos de normatizações que adentram o cotidiano dos serviços de saúde e interferem na saúde da população.

\section{Resultados e Discussão}

O cuidado em saúde é permeado por tensões que revelam as apostas estético-políticas das instituições e atores envolvidos neste processo. Deste ponto de vista, a cada dia, temos nos defrontado com os atravessamentos que o sistema judiciário vem produzindo no campo das políticas públicas da saúde.

Extensivamente, no campo da judicialização em saúde, é discutido o fenômeno pelo qual o judiciário determina que o executivo oferte certas tecnologias em saúde, principalmente insumos e medicamentos, independente de fluxos ou organização dos serviços. Situação polêmica segundo diversos aspectos.

Entretanto, para, além disso, seguimos observando ações que se promovem por parte do judiciário com uma sofisticação ainda maior, referente a uma profunda intervenção na vida dos usuários, com papel determinante em ações não só do poder executivo, mas, inclusive, tencionando o arcabouço jurídicolegal segundo certas intencionalidades.

$\mathrm{Na}$ área específica da saúde mental, temos observado movimentos sobre como se produzir o cuidado em saúde e suas implicações para com a liberdade. Nesta direção, sustentar a luta antimanicomial é um desafio dentro dos serviços de saúde ou na sociedade, pois há em disputa outras apostas flagrantemente opostas à liberdade e possibilidade de escolhas dos sujeitos. Tais apostas, muitas vezes rechaçadas pelas instituições judiciárias (apesar de fomentadas por diversos campos da saúde), consideram razoáveis internações, como aquelas por tempo determinado, com uma perspectiva específica sobre o problema do uso abusivo de álcool e outras drogas ou mesmo aquelas a perder de vista, com a justificativa de uma periculosidade iminente e sem medidas, só aplacado pelo encarceramento, disciplinarização e apartamento do sujeito da sociedade.

\begin{abstract}
A reforma psiquiátrica é hoje desafiada a responder a outro e novo desafio: Qual o lugar e como responder aos que encontram nas drogas o modo de se experimentar humano? [...] A política do mal- estar deve, ao mesmo tempo, ser capaz de ofertar uma clínica cidadã, tratando em liberdade e com dignidade os que sofrem, e intervir sobre a cultura da exclusão que os ameaça. Uma clínica antimanicomial da toxicomania não pode se furtar a questionar os nomes com os quais a sociedade define a drogadição e os sujeitos que se intoxicam. Drogado, delinquente, criminoso, pecador ou doente são, sem exceção, identidades marginais e, como tais, coladas a um destino previamente traçado: fora da cidadania. Desconstruir tais identidades é condição preliminar para tratar a singularidade de cada experiência de drogadição. 4:204
\end{abstract}

Como mais um dos capítulos deste relacionamento tenso, vivenciamos atualmente o fenômeno que se instituiu chamar de "Mães Órfãs".

\section{Mães Órfãs: que fenômeno é este?}

Denominamos “Mães Órfãs" a situação de 
mães em circunstância de vulnerabilidade que têm perdido seus bebês para a tutela do Estado de forma compulsória.

Em BH, em especial nos últimos 3 (três) anos, há um crescente número de crianças que têm sido abrigadas compulsoriamente com a justificativa de que a mãe, pai e/ou família extensa não se mostram capazes de oferecer o cuidado necessário aos bebês. Este aumento vem se ampliando e aprofundando a discussão frente a dispositivos legais, como o Estatuto da Criança e Adolescência (ECA), ao mesmo tempo em que é fomentado por dispositivos infra-legais elaborados pelo Estado/Judiciário mineiro, como recomendações/portaria do Ministério Público Estadual (MP) e Vara Cível da Infância e da Juventude (VCIJBH).

Como grupo de pesquisa, viemos desde 2014 acompanhando casos de mulheres que tiveram seus filhos abrigados.

Via de regra, as pessoas em situação de rua, com quadros de sofrimento psíquico e/ou em uso de álcool e/ou outras drogas são consideradas "vulneráveis". Nestas ocasiões, o papel do Estado deveria se direcionar a promover ações para o fortalecimento destes sujeitos, agindo a partir de demandas e especificidades que apresentam. Contudo, assistimos a relatos de frequentes violações dos direitos humanos e desrespeito ao arcabouço legal que determinam os direitos da criança e família, fenômeno paradoxal, uma vez que tem sido respaldado por instituições que deveriam ser as guardiãs da justiça. Vê-se que este é um campo de permanentes disputas em que entram em cena o sistema judicial, o sistema de proteção social, o sistema de saúde, operando uns sobre os outros.

Do ponto de vista do judiciário, as Recomendações no $05^{5}$ e n은 $06^{6}$ de 2014 da 23a PJIJBH e a Portaria no 03/VCIJBH/2016 são normas que têm orientado o processo de expropriação dos bebês em Belo Horizonte. A primeira, destinada às maternidades, e a segunda, aos serviços de Atenção Básica à Saúde, orientam os trabalhadores a comunicarem à Vara da Infância e da Juventude de Belo Horizonte/VCIJBH as situações de vulnerabilidade para que o judiciário tome providências conforme seu julgamento. A Portaria n 03/VCIJBH/2016 ratifica esse posicionamento e imputa responsabilidade criminal aos profissionais da saúde que não atenderem às exigências do judiciário. Este documento também determina a comunicação à VCIJBH do nascimento de criança de pais que tenham alguma dependência química ou com histórico de situação de rua no prazo de 48 (quarenta e oito) horas a partir do nascimento da criança, para que estas sejam levadas a entidades de acolhimento. Não há, contudo, qualquer informação na referida portaria de alguma medida que respalde o direito à saúde, à maternagem e dignidade dos pais que estejam nas situações de vulnerabilidade citadas. 
Tais documentos desconsideram as singularidades existentes nas vidas dessas mães e, neste cenário, os profissionais de saúde são capturados em sua autonomia. A leitura dos documentos remete a lógica utilitarista do outro como coisa e a desconsideração da possibilidade de produção de vida diante de situações que transcendem os objetivos capitalísticos. ${ }^{8}$

Do ponto de vista da proteção social, o $\mathrm{ECA}^{9}$ estabelece, por sua vez, o fortalecimento de vínculos familiares como uma medida protetiva à criança e ao adolescente e entende o acolhimento institucional como excepcional e provisório. Esta Lei designa o Conselho Tutelar como órgão responsável por zelar pelo cumprimento dos direitos da criança e do adolescente e explicita que a suspensão do poder familiar poderá ocorrer apenas depois de exauridas todas as possibilidades de sustentação da criança ou do adolescente junto à sua família biológica.

Entretanto, em BH, a própria legislação municipal desrespeita as determinações do ECA. Crianças pobres são separadas de suas mães sem o consentimento destas e prevalece um regime de verdade que desconsidera as multiplicidades de famílias existentes. ${ }^{10}$ Neste cenário a ONG "Bem Nascer"11 que tem por princípio compartilhar informações acerca de práticas humanizadas no nascimento, lança a campanha "De quem é esse bebê", pedindo o respeito às singularidades de cada mãe e a criação de uma rede de apoio e tratamento para estas mulheres.

Do ponto de vista do Sistema de Saúde, o Ministério da Saúde produziu nos últimos anos um conjunto de publicações a respeito da população em situação de rua. ${ }^{12-13}$ Tais documentos apontam a responsabilidade do Estado em assegurar direitos humanos a mulheres, adolescentes e crianças que estão em situação de vulnerabilidades e que têm seus direitos sociais violados.

Ainda no campo da saúde, é importante situar movimentos do Conselho Municipal de Saúde que produziu, dentre outros elementos, um informativo revelando um rápido processo de adoção de bebês em $\mathrm{BH}$ sem nenhum diálogo com a família biológica da criança. ${ }^{14}$ Neste contexto, os servidores da Secretaria Municipal de Saúde (SMSA/BH) têm participado da defesa do direito à maternagem e da criação de fluxos assistenciais com o objetivo de considerar as singularidades de cada caso e a discussão relacionada ao enfrentamento das vulnerabilidades. ${ }^{15} \mathrm{Na} 14$ ạ Conferência Municipal de Saúde de BH foi aprovada moção de repúdio à separação forçada de bebês de suas mães. ${ }^{16}$

A Secretaria Estadual de Saúde de Minas Gerais (SES/MG), por sua vez, realizou um evento de lançamento da Resolução № $206^{17} \mathrm{com}$ orientações aos profissionais de saúde e serviços públicos para o atendimento às mulheres e adolescentes usuárias de crack e outras drogas e a seus filhos recém-nascidos. 
Neste contexto de disputa, as manifestações sociais asseguraram a suspensão da Portaria $\mathrm{n}$ 은 03/VCIJBH/2016 em agosto de 2017 e uma minuta de nova Portaria foi encaminhada pela VCIJBH à Corregedoria Geral de Justiça do Estado. Em setembro de 2017, o Programa Pólos de Cidadania da Faculdade de Direito e Ciências do Estado da UFMG ${ }^{18}$ divulga várias considerações acerca dessa minuta e destaca a urgência da implementação de estudos multidisciplinares que possam contribuir para a promoção, proteção e defesa do direito à convivência familiar e comunitária.

Esses são alguns exemplos de instrumentos normativos e manifestações coletivas que têm tornado explícitos posicionamentos e disputas com desdobramentos importantes para a vida de mães marcadas pelo poder do Estado em BH.

\section{Considerações finais}

O Judiciário: faces de uma instituição de soberania dentro de um estado democrático de direito

$\mathrm{Na}$ atualidade, vivemos momentos de acirramentos importantes entre instituições, coletivos e apostas ético-políticas no que diz respeito ao governo da vida de si e dos outros, considerando o arranjo societário no qual estamos imersos.

Subsistem instantes de profundas rupturas e tensionamentos nos quais até colocamos em interrogação se ainda caminhamos como cidadãos em um estado democrático de direito. Neste processo, a judicialização de ações sobre a vida de alguns considerados "vulneráveis" ganha centralidade como pauta que nos exige posicionamento sobre qual sociedade estamos inseridos e para onde queremos ir.

Nos relatos de mães e trabalhadores, a violência cotidiana, ditada pelo poder do Estado, aparece marcada por julgamentos morais, massacre de desejos maternais, tentativa de controle total do corpo do outro. As mães, ao gerarem seus filhos e darem entrada numa maternidade pública, ganham a nomeação estigmatizada de "mães vulneráveis". São identificadas pelos profissionais das maternidades como moradoras de rua e usuárias de drogas e essa denominação, inscrita em sua história, passa a ser suficiente para eliminar toda uma produção de vida e de rede anterior. Nesta perspectiva, o Estado que tem se mostrado violador e silenciador reproduz um controle generalizado sob os corpos das mulheres, negras, pobres, usuárias de drogas e em situação de rua.

Frente aos desafios singulares da produção do cuidado e da atuação da justiça em defesa da vida, como caminharmos com instituições que colocam certas apostas ético-estéticas moralizantes e totais, promovendo o governo dos outros numa perspectiva de submissão de mundos e controle sobre suas vidas?

Defrontamo-nos com a reatualizarão de estratégias de controle sobre a vida, 
constituindo os chamados "anormais do desejo" $^{8}$ engendrados pelas instituições do judiciário. E estas estratégias reatualizadas têm tencionado a produção do cuidado por dentro dos serviços de saúde no sentido de discriminar e reforçar que estas mulheres não têm o mesmo direito à maternagem por estarem em situação de vulnerabilidade.

A judicialização de vidas vulneráveis e a insuficiente porosidade das mobilizações em defesa do direito à maternidade em nossa sociedade têm mostrado arranjos sociais que interferem na construção de novas possibilidades de cuidado em saúde.

As ações segregativas têm deixado marcas irreparáveis na vida destas mulheres. Violadas no seu direito de exercer a maternidade, elas voltam, por vezes, à situação de vulnerabilidade na qual se encontravam, prejudicadas psiquicamente, além de romperem os vínculos construídos nas redes de proteção e cuidado.

Entre os profissionais de saúde, os discursos aparecem polarizados sobre o binômio de proteção, ora destinada para a mãe ora destinada para o bebê, não se pensando na família que está sendo constituída e nas diversas possibilidades desta relação mãe-filho para produção de vida e sujeitos mais plenos. $\mathrm{E}$ quando não há posicionamento ético-político por parte dos trabalhadores de saúde de que estas duas vidas valem muito sem preponderância de uma sobre outra, a efetivação de políticas públicas como a do SUS é exposta ao processo de judicialização, deixando nas mãos do Estado ou do juiz a produção de verdades absolutas, que determinam homogeneidade para uma multiplicidade de existências.

Nestas encruzilhadas há que se perguntar: quais vidas realmente importam?

Nota

\footnotetext{
' Ver o texto: Silva KL, Magalhães RV, Ferreira VL, Capistrano D. Sofia e Tantas Outras Mulheres Usuárias de Crack e Seus Filhos: quando a (in)capacidade de gerir sua própria vida afeta a produção do cuidado. In: Feuerwerker LCM, Bertussi DC, Merhy, EE (Organizadores). Avaliação Compartilhada do Cuidado em Saúde: surpreendendo o instituído nas Redes. Rio de Janeiro: Hexis; 2016. p. 292-307. Produzido como resultado da Pesquisa Rede de Avaliação Compartilhada (RAC).
}

\section{Referências}

${ }^{1}$ Hobbes T de M. Leviatã. Tradução de João Paulo Monteiro e Maria Beatriz Nizza da Silva. São Paulo: Editora Nova Cultural; 1997. Os Pensadores

${ }^{2}$ Foucault M. A Verdade e as formas jurídicas. 3. ed. Rio de Janeiro: Nau Editora; 2002.

${ }^{3}$ Castel RA. Gestão de riscos. Rio de Janeiro: Editora Francisco Alves; 1987. 
${ }^{4}$ Silva RA. No meio de todo o caminho, sempre haverá uma pedra. Responsabilidades. 2011 2012; 1(2):203-214. [Internet]. 2011 [citado 02 nov 2017]. Disponível em: http://www8.tjmg. jus.br/presidencia/programanovosrumos/pai_pj/ revista/edicao02/3.pdf

${ }^{5}$ Recomendação no 5/PJIJCBH/MPMG, de 16 de junho de 2014. Recomendação aos médicos, profissionais de saúde, diretores, gerentes e responsáveis por maternidades e estabelecimentos de saúde. Belo Horizonte: Ministério Público do Estado de Minas Gerais; 2014.

${ }^{6}$ Recomendação no 6/ PJIJCBH/MPMG, de 06 de agosto de 2014. Recomendação aos médicos, profissionais de saúde, Agentes Comunitários de Saúde, gerentes e responsáveis por Unidades Básicas de Saúde. Belo Horizonte: Ministério Público do Estado de Minas Gerais; 2014.

${ }^{7}$ Portaria no 3/VCIJBH, de 22 de julho de 2016. Dispõe sobre o procedimento para encaminhamento de crianças recémnascidas e dos genitores ao Juízo da Infância e da Juventude, assim como, oitiva destes, nos casos de graves suspeitas de situação de risco, e sobre o procedimento para aplicação de medidas de proteção. Diário do Judiciário Eletrônico TJMG. [Internet] 201625 jul [citado 04 mai 2017]:29-33. Disponível em: http:// ftp.tjmg.jus.br/juridico/diario/index.jsp? dia $=2207 \&$ completa $=2$ inst\%7Cadm.

${ }^{8}$ Merhy EE. Anormais do desejo: os novos não humanos? Os sinais que vêm da vida cotidiana e da rua. Grupo de Trabalho de Álcool e Outras Drogas. Drogas e Cidadania em Debate. Brasília: Conselho Federal de Psicologia; 2012. p.9-18.

'Lei № 8.069, de 13 de julho de 1990. Estatuto da Criança e do Adolescente. Diário Oficial da República Federativa do Brasil, Brasília. [Internet] 1990 [citado 21 ago 2017]. Disponível em: http://www.planalto.gov.br/ccivil_03/ LEIS/L8069.htm.

${ }^{10}$ Foucault M. Microfísica do poder. Rio de Janeiro: Edições Graal; 2001.

${ }^{11}$ Bem Nascer. ONG Bem Nascer. [Internet]; [citado 05 jul 2017]. Disponível em: .

${ }^{12}$ Ministério da Saúde (BR). Manual sobre o cuidado à saúde junto à população em situação de rua. Brasília: Ministério da Saúde; 2012.

${ }^{13}$ Ministério da Saúde (BR). Saúde da população em situação de rua: um direito humano. Brasília: Ministério da Saúde; 2014.

${ }^{14}$ Conselho Municipal de Saúde de Belo Horizonte. Informativo do Conselho Municipal de Saúde de Belo Horizonte [Internet]. 50. ed. Belo Horizonte, $2015 . \quad$ [citado 07 jul 2017]. Disponível em: http://portalpbh.pbh.gov.br/ $\mathrm{pbh} / \mathrm{ecp} /$ comunidade.do?evento=portlet\&pldPIc=ecpTaxonomiaMenuPortal\&app=cms\&tax=17971\&lang=pt_BR\&pg= 7122\& $\operatorname{taxp}=0 \&$.

${ }^{15}$ Secretaria Municipal de Saúde de Belo Horizonte. Ofício Secretaria Municipal de Saúde nำ1314, de 26 de dezembro de 2014. Dispõe sobre as recomendações no05 e no 06 de 2014 e apresenta fluxograma de atendimento às mães usuárias de drogas no município de Belo Horizonte. Belo Horizonte: SMS; 26 dez 2014.

${ }^{16}$ Conselho Municipal de Saúde de Belo Horizonte. 14a Conferência Municipal de Saúde de BH. Relatório Final das Moções Aprovadas [Internet]. Belo Horizonte: CMS; 2017. [citado 05 jul 2017]. Disponível em: http://portalpbh.pbh.gov.br/pbh/ ecp/noticia.do?evento=portlet\&pAc =not\&idConteudo=258559\&pldPIc=\&app=salanoticias .

${ }^{17}$ Resolução Conjunta SES- MG/ SEDPAC- MG/ SEDESE-MG no 206, de 18 de Novembro de 2016. Autoriza a divulgação de orientações para os Serviços Públicos de Atendimento às mulheres e adolescentes usuárias de crack e outras drogas e a seus filhos recém- nascidos. Diário do Judiciário Eletrônico TJMG. 18 nov. 2016. [Internet]. 2016. [citado 21 ago. 2017]. Disponivel em: http://www.saude.mg.gov.br/images/documentos/Resolu\%C3\%A7\%C3\%A3 0\%20Conjunta_206.pdf.

${ }^{18}$ Pólos de Cidadania. Considerações sobre a minuta de portaria em substituição à portaria no03/vcijbh/2016 e contribuições para o debate. Belo Horizonte: Faculdade de Direito e Ciências do Estado da Universidade Federal de Minas Gerais; 2017. 